\title{
Grupo Genético e Nível Nutricional Pós-Parto na Produção e Composição do Leite de Vacas de Corte
}

\author{
João Restle ${ }^{1}$, Paulo Santana Pacheco ${ }^{2}$, José Luiz Moletta ${ }^{3}$, Ivan Luiz Brondani ${ }^{4}$, Liliane Cerdótes ${ }^{2}$
}

RESUMO - O objetivo deste experimento foi avaliar a produção média diária e composição percentual do leite de vacas Charolês (CH) e Nelore (NE), mantidas em pastagem nativa (PN) ou pastagem cultivada (PC) de inverno (aveia mais azevém) e de verão (capim papuã). Foram utilizadas sessenta vacas, por um período de 182 dias, amamentando bezerros puros ou mestiços, distribuídas de acordo com os tratamentos: $\mathrm{CHPN}=$ Vacas CH mantidas em PN; NEPN = Vacas NE mantidas em PN; CHPC = Vacas CH mantidas em PC; e NEPC $=$ Vacas NE mantidas em PC. Vacas mantidas em PC apresentaram curva de lactação com comportamento quadrático, com média de 4,80 L/dia, enquanto que vacas mantidas em PN reduziram linearmente a produção, com média de 3,98 L/dia. A produção de leite entre vacas $\mathrm{CH}$ e NE apresentou similaridade (4,50 e 4,28 L/dia, respectivamente). Os grupos genéticos diferiram em todos os componentes do leite, sendo os valores médios para gordura (GOR), extrato seco total (EST), extrato seco desengordurado (ESD) e lactose (LAC) de 4,$93 ; 13,81 ; 8,91 ;$ e 5,14\%, respectivamente, para vacas NE e 4,35; 13,07; 8,74; e 4,94\%, respectivamente, para vacas CH. Vacas adultas mantidas em PC produziram mais leite $(5,61 \mathrm{~L} /$ dia $)$ em relação às jovens $(5,00 \mathrm{~L} /$ dia $)$ e estas mais do que as velhas $(3,77 \mathrm{~L} /$ dia $)$. No entanto, vacas jovens apresentaram leite com maior teor de GOR e EST do que adultas (4,92 e 13,68\% vs 4,51 e 13,27\%, respectivamente). O grupo genético do bezerro não influenciou a produção de leite das vacas. Foi verificada interação entre grupo genético da vaca e dia de lactação para teor de GOR e EST, sendo que em vacas NE o comportamento foi quadrático para ambas características e em vacas CH o comportamento foi linear. Já os teores de ESD e LAC variaram de acordo com o dia de lactação. O uso de pastagem cultivada de inverno e de verão no período pós-parto promoveu maior produção de leite em vacas de corte Charolês e Nelore, bem como em vacas jovens e adultas, quando comparadas com vacas mantidas em pastagem nativa.

Palavras-chave: Charolês, gordura no leite, idade da vaca, Nelore, pastagem cultivada, pastagem nativa

\section{Genetic Group and Postpartum Nutritional Level on the Milk Yield and Composition of Beef Cows}

ABSTRACT - The objective of this experiment was to evaluate the composition and average daily milk yield of Charolais (CH) and Nellore (NE) cows, mantained on native pasture (NP) or winter (oat plus italian rye grass) and summer (alexander grass) cultivated pasture (CP). Sixty cows nursing straightbred or crossbred calfs were used, during 182 days, according to the following treatments: $\mathrm{CHNP}$ $=\mathrm{CH}$ cows mantained on NP; NENP $=\mathrm{NE}$ cows mantained on $\mathrm{NP} ; \mathrm{CHCP}=\mathrm{CH}$ cows mantained on $\mathrm{CP}$; and $\mathrm{NECP}=\mathrm{NE}$ cows mantained on CP. Cows mantained on CP showed lactation curve with quadratic behaviour, with mean of $4.80 \mathrm{~L} /$ day, while cows mantained on NP reduced linearly the production, with mean of $3.98 \mathrm{~L} /$ day. The milk yield between $\mathrm{CH}$ and NE cows showed similarity $(4.50 \mathrm{vs} 4.28$ L/day). The genetic groups differed in all milk components, being the mean values for fat (FAT), total dry extract (TDE), free-fat dry extract (NDE) and lactose (LAC) of 4.93; 13.81; 8.91; and 5.14\%, respectively, for NE cows; and 4.35; 13.07; 8.74; and 4.94\%, respectively, for $\mathrm{CH}$ cows. Adult cows mantained on $\mathrm{CP}$ produced more milk (5.61 L/day) in relation to young cows (5.00 L/day) and these more than old cows (3.77 L/day). However, young cows showed milk with higher FAT and TDE content than adult cows (4.92 and $13.68 \%$ vs 4.51 and $13.27 \%$, respectively). The calf genetic group didn't influence the milk yield of cows. The interaction between cow genetic group and lactation day was significant for FAT and TDE content, showing for NE cows a quadratic behaviour for both characteristics and for $\mathrm{CH}$ cows a linear model. The NDE and LAC varied according to lactation day. The use of winter and summer cultivated pasture during the postpartum period promoted higher milk production for Charolais and Nellore cows, as well as for young and adult cows, when compared to cows kept on native pasture.

Key Words: Charolais, milk fat, cow age, Nellore, cultivated pasture, native pasture

\section{Introdução}

Vacas de corte com maior produção de leite, normalmente possuem bezerros que apresentam melhores pesos ao desmame. A correlação entre a produção de leite da vaca e o peso ao desmame do bezerro é positiva e alta, variando de 0,44 a 0,88 (Rutledge et al., 1971; Totusek et al., 1973; Ribeiro \& Restle, 1991).

1 Engenheiro-Agrônomo, PhD. Pesquisador do CNPq. Professor Titular do Departamento de Zootecnia da UFSM, Campus Camobi, CEP: 97119-900, Santa Maria - RS. E.mail: jorestle@ccr.ufsm.br

2 Zootecnista. Aluno do Programa de Pós-graduação em Zootecnia da UFSM.

3 Zootecnista, MSc. Pesquisador do IAPAR - Ponta Grossa, PR.

4 Zootecnista, Dr. Professor Adjunto do Departamento de Zootecnia da UFSM. 
Os dois fatores que afetam a produção de leite e como consequiência o desempenho do bezerro são o ambiental e o genético. Quanto ao fator ambiental, os mais comumente considerados são: a idade da vaca ao parto; o ano, o mês e a estação de parição; e principalmente o nível nutricional ao qual os animais estão submetidos. Entre os fatores não ambientais ou genéticos, destaca-se a composição genética dos animais, geralmente expressa em termos de grau de sangue ou grupo genético; e o tamanho da vaca. Há também outros fatores que estão ligados ao bezerro, como seu grupo genético ou efeito paterno e sexo.

Quanto à contribuição do efeito da idade da vaca na variação da produção de leite, de maneira geral, a maioria dos autores citam que há aumento até as vacas atingirem sua maturidade fisiológica, declinando logo após (Neville Jr. et al., 1974; Rovira, 1974; Robison et al., 1978; Souza et al., 1996).

Já o efeito da data de nascimento sobre a produção de leite está associado principalmente à disponibilidade e qualidade da forragem durante o ano (Rovira, 1996). Alencar et al. (1988) acrescentam que as diferenças em produção devido ao efeito de mês estão relacionadas com modificações de clima, tais como temperatura, umidade, precipitação pluviométrica e luminosidade, que afetam diretamente a disponibilidade das forrageiras.

O efeito nutricional é tido como o mais importante fator a afetar a produção de leite (Dunn et al., 1965; Richardson et al., 1977; Polli \& Lobato, 1985; Senna, 1996; Quadros \& Lobato, 1997). Os resultados do estudo de Ribeiro et al. (1991) comprovaram que vacas que permaneceram em pastagem cultivada no período pré e pós-parto produziram mais leite do que as que permaneceram durante todo o período em pastagem nativa (4,0 vs 3,0 L/dia).

Quanto ao efeito genético sobre a produção de leite, Melton et al. (1967), trabalhando com três raças de corte: Charolês, Aberdeen Angus e Hereford verificaram, respectivamente, 785; 664; e $581 \mathrm{~kg}$ de leite no período de 175 dias de lactação em pastagem cultivada de aveia, concordando com os resultados de Ribeiro et al. (1991), que verificaram maior produção de leite em vacas Charolês, quando comparadas às Aberdeen Angus, em 182 dias de lactação.

As informações existentes na literatura sobre a influência do sexo do bezerro na produção de leite são contrastantes, onde pesquisas demonstram haver influência (Melton et al., 1967; Rutledge et al., 1971) e outras citam não haver influência do sexo do bezerro na produção de leite da vaca (Wilson et al., 1969; Alencar et al., 1988; Ribeiro et al., 1991).

Não só a quantidade de leite é importante, mas também a sua composição, uma vez que seus constituintes devem estar contidos em proporções adequadas para um completo desenvolvimento inicial do bezerro. Segundo Holloway et al. (1975) e Bowden (1981), a composição do leite pode ser influenciada pelo grupo genético da vaca, estádio da lactação e nível alimentar ao qual a vaca está submetida.

O presente estudo foi conduzido com o objetivo de avaliar a produção e a composição do leite de vacas de corte de dois grupos genéticos (Charolês ou Nelore), submetidas a dois tipos de pastagem (pastagem nativa ou cultivada de inverno e verão) no período pós-parto, amamentando bezerros puros ou mestiços.

\section{Material e Métodos}

Oexperimentofoi conduzidono SetordeBovinocultura de Corte do Departamento de Zootecnia da Universidade Federal de Santa Maria, no município de Santa Maria, estado do Rio Grande do Sul, na região fisiográfica Depressão Central, onde segundo classificação de Köppen, apresenta clima subtropical úmido (cfa).

Foram utilizadas 60 vacas, primíparas e pluríparas, com idade variando de três a treze anos, sendo 30 do grupo genético Charolês $(\mathrm{CH})$ e 30 do grupo genético Nelore (NE), tomadas ao acaso do mesmo rebanho experimental. As vacas amamentavam bezerros definidos (CH ou NE) ou mestiços ( $1 / 2 \mathrm{CH} 1 / 2 \mathrm{NE}$ ou $1 / 2 \mathrm{NE} 1 / 2 \mathrm{CH}$ ). O desmame ocorreu quando a idade média dos bezerros era de 217 dias. Contudo, a última determinação da produção de leite das vacas ocorreu aos 182 dias.

Foram estudados os seguintes tratamentos:

CHPN - Vacas CH mantidas em pastagem nativa (PN), do parto ao desmame dos bezerros;

NEPN - Vacas NE mantidas em PN, do parto ao desmame dos bezerros;

CHPC - Vacas $\mathrm{CH}$ mantidas em pastagem cultivada (PC) de aveia (Avena sativa) mais azevém (Lollium multiflorum) do parto até o final do mês de novembro e após em pastagem de capim-papuã (Brachiaria plantagínea), até o desmame dos bezerros;

NEPC - Vacas NE mantidas em PC de aveia (Avena sativa) mais azevém (Lollium multiflorum) do parto até o final do mês de novembro e após em pastagem de capim papuã (Brachiaria plantagínea), até o desmame dos bezerros. 
Nos tratamentos os animais ficaram equilibrados pela ordem de parição e idade da vaca.

Para o CHPC e NEPC foi utilizada uma área de 17 ha, com pastagem de inverno (aveia mais azevém) e outros 17 ha com pastagem de verão, sendo a lotação/ha de 1,76 vacas com bezerro ao pé, tanto em PC de inverno como de verão. Para o CHPN e NEPN foi utilizada uma área de 30 ha de PN, sendo a lotação/ha de 1,0 vaca com bezerro ao pé.

Avaliou-se a massa de forragem disponível, por intermédio da técnica da dupla amostragem (Wilm et al., 1944). Foram coletadas amostras da forragem cortada rente ao solo, para posterior determinação da digestibilidade in vitro da matéria orgânica (DIVMO) e da proteína bruta (PB).

O método utilizado para determinar a produção de leite foi o direto, com ordenha manual. As avaliações foram realizadas 14 dias pós-parto e a partir daí com intervalos de 28 dias até os 182 dias. As vacas eram separadas de seus bezerros pela manhã (um dia antes da ordenha) e soltas em piquete anexo. Por volta das $18 \mathrm{~h}$, eram recolhidas novamente até o centro de manejo, permanecendo com o bezerro por 30 minutos, tempo suficiente para esgotar o úbere. Após mamarem, os bezerros eram separados novamente das vacas e ficavam contidos no centro de manejo, sendo as vacas soltas em piquete com pasto e água, no dia seguinte, às $6 \mathrm{~h}$, iniciava-se a ordenha. Para realização da ordenha, a vaca era contida pelo pescoço e a pata traseira esquerda era amarrada com corda, recebendo então, $3 \mathrm{~mL}$ de ocitocina via intramuscular, a fim de facilitar a descida do leite. A ordenha foi realizada, após o úbere ser lavado e massageado, apenas nos dois quartos do lado direito do úbere, com duração em torno de 5 minutos. A produção obtida era multiplicada por dois, para se ter a produção do úbere, sendo também corrigida para 24 horas por intermédio da seguinte equação:

Produção leite $($ L/dia $)=(($ produção dos dois quartos do úbere $) * 2)$ * 60 minutos $* 24 \mathrm{~h}$

Tempo (minutos) entre a última mamada e a ordenha

Posteriormente à ordenha, foram coletadas amostras de aproximadamente $300 \mathrm{~mL}$, que foram enviadas ao laboratório para determinação da percentagem de gordura (GOR), lactose (LAC), extrato seco total (EST) e extrato seco desengordurado (ESD) do leite. Também foi realizada a correção da produção de leite para $4 \%$ de gordura, utilizando a seguinte equação: $\mathrm{L} 4 \%=0,4 \mathrm{P}+0,15 \mathrm{P} * \% \mathrm{G}$, em que: $\mathrm{L} 4 \%=$ produção de leite corrigida; $\mathrm{P}=$ produção de leite (L/dia) e $\% \mathrm{G}=$ porcentagem de gordura do leite.

O delineamento experimental utilizado foi o inteiramente casualizado, sendo os dados submetidos à análise de variância, teste $\mathrm{F}$ e teste de Tukey, quando o $\mathrm{F}$ foi significativo a $5 \%$, utilizando o programa estatístico SAS (1997). O modelo estatístico utilizado foi:

Yijklmno $=\mathrm{m}+\mathrm{NTi}+\mathrm{GGj}+\mathrm{Pk}+\mathrm{RTl}(\mathrm{GG}) \mathrm{j}+$ $\left(\mathrm{P}^{*} \mathrm{GG}\right) \mathrm{kj}+\mathrm{Sm}+\left(\mathrm{GG}^{*} \mathrm{~S}\right) \mathrm{jm}+\mathrm{IVn}+(\mathrm{IV} * \mathrm{~S}) \mathrm{nm}+$ $\left(\mathrm{IV}^{*} \mathrm{P}\right) \mathrm{nk}+(\mathrm{GG} * \mathrm{IV}) \mathrm{jn}+\mathrm{DIAo}+(\mathrm{P} * \mathrm{DIA}) \mathrm{ko}+$ $\left(G^{*}\right.$ DIA $) j o+\left(P^{*}\right.$ GG*DIA $) k j o+$ eijklmno

em que: Yijklmno = variáveis dependentes; $\mathrm{m}=$ média geral de todas as observações; NTi = efeito da "ordem de nascimento do bezerro" de ordem "i"; GGj = efeito do grupo genético da vaca de ordem "j", sendo $1=$ Charolês e $2=$ Nelore; $\mathrm{Pk}=$ efeito do tipo de pastagem de ordem "k", sendo $1=$ pastagem cultivada e 2=pastagem nativa; RTl (GG)j = efeito da raça do bezerro de ordem "l" sendo $1=$ Charolês, $2=$ Nelore, $3=1 / 2$ Charolês $1 / 2$ Nelore e $4=1 / 2$ Nelore $1 / 2$ Charolês dentro do grupo genético da vaca de ordem " $\mathrm{j}$; $\left(\mathrm{P}^{*} \mathrm{GG}\right) \mathrm{kj}$ = interação entre k-ésimo tipo de pastagem e j-ésimo grupo genético da vaca; $\mathrm{Sm}=$ efeito do sexo do bezerro de ordem "m", sendo 1=macho e 2=fêmea; $\left(G^{*} S\right) j m$ = interação entre j-ésimo grupo genético da vaca e m-ésimo sexo do bezerro; IVn = efeito da classe de idade da vaca de ordem "n", sendo $1=$ jovens, 2=adultas e 3=velhas; $(I V * S) n m$ = interação entre n-ésima idade da vaca e m-ésimo sexo do bezerro; $\left(\mathrm{IV}^{*} \mathrm{P}\right) \mathrm{nk}=$ interação entre n-ésima idade da vaca e k-ésimo tipo de pastagem; $\left(\mathrm{GG}^{*} \mathrm{IV}\right) \mathrm{jn}=$ interação entre j-ésimo grupo genético da vaca e nésima idade da vaca; DIAo = efeito do dia de lactação de ordem "o"; (P*DIA)ko = interação entre o k-ésimo tipo de pastagem e o-ésimo dia de lactação; (GG*DIA)jo = interação entre o j-ésimo grupo genético da vaca e o-ésimo dia de lactação; $\left(\mathrm{P}^{*} \mathrm{GG} \mathrm{G}^{*} \mathrm{DIA}\right) \mathrm{kjo}=$ interação entre k-ésimo tipo de pastagem, j-ésimo grupo genético da vaca e o-ésimo dia de lactação; eijklmno = erro aleatório residual, $\operatorname{NID}\left(0, \sigma^{2}\right)$.

Para estimativas das equações de regressão, o efeito de período (dias de lactação) sobre as variáveis dependentes foi submetido à análise de regressão polinomial. A ordem de nascimento do bezerro foi 
utilizada no modelo como covariável.

\section{Resultados e Discussão}

\section{Disponibilidade e qualidade da pastagem}

A massa média de forragem disponível na pastagem cultivada de inverno foi de $1.252 \mathrm{~kg}$ de MS/ha e na de verão de $1.879,6 \mathrm{~kg}$ de MS/ha. Já na pastagem nativa foi de $1.654,4 \mathrm{~kg}$ de $\mathrm{MS} / \mathrm{ha}$. A digestibilidade in vitro da matéria orgânica (DIVMO) e o teor de proteína bruta (PB), citados na mesma ordem, foram de 59,4 e $9,7 \% ; 58,9$ e $6,1 \% ; 36,8$ e $5,6 \%$. Verificouse que animais mantidos em pastagem cultivada tiveram a disposição alimento de melhor qualidade representado pela maior concentração de matéria orgânica digestível e de proteína bruta.

\section{Produção de leite}

Não foi verificada interação significativa entre tratamento alimentar, grupo genético da vaca e dia de lactação para produção média diária de leite. Embora esta interação não tenha sido significativa, os resultados do comportamento da produção de leite estão representados na Figura 1. Nota-se nesta Figura que quando o tratamento alimentar foi composto por pastagem nativa, a produção média diária de leite apresentou comportamento linear decrescente, tanto para vacas Charolês quanto para as Nelore. Já quando o nível nutricional foi melhorado com a utilização de pastagem cultivada, o comportamento

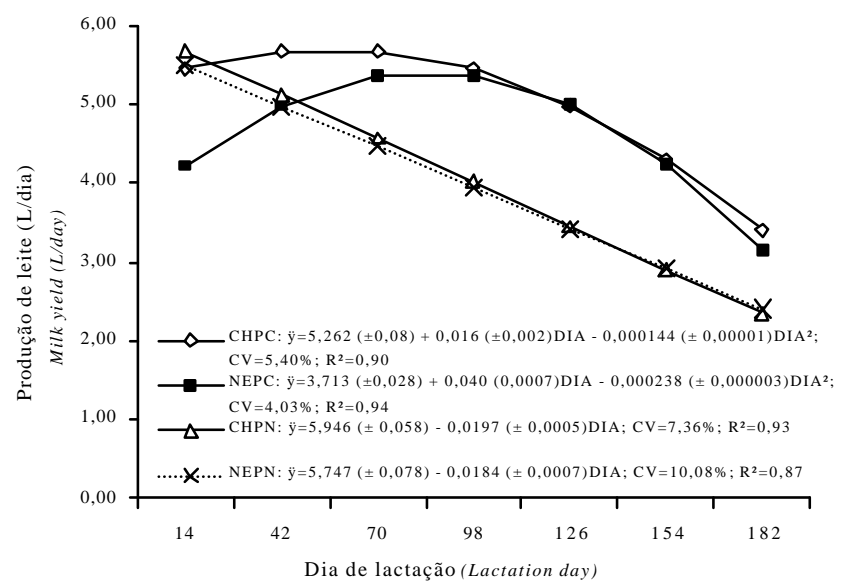

Figura 1 - Produção de leite de acordo com o grupo genético da vaca, tratamento alimentar e dia de lactação.

Figure 1 - Milk yield according to cow genetic group, food treatment and lactation day. verificado foi quadrático, onde vacas Charolês apresentaram produção máxima estimada de 5,71 litros aos 55 dias de lactação, e vacas Nelore com 5,40 litros aos 84 dias de lactação.

Houve interação significativa $(\mathrm{P}=0,0164)$ entre tratamento alimentar e dia de lactação, conforme demonstrado na Tabela 1, sendo que a produção de leite de vacas mantidas em pastagem cultivada apresentou comportamento quadrático, com produção máxima estimada de 5,47 L atingido aos 72 dias de lactação. Já para as vacas mantidas em pastagem nativa, houve queda linear de 0,019 L/dia. Na média, a produção de leite de vacas mantidas em pastagem cultivada foi $20,6 \%$ superior àquelas mantidas em pastagem nativa (4,80 vs 3,98 L/dia; $\mathrm{P}=0,0001)$.

Estes resultados são explicados principalmente pela melhor qualidade nutricional (PB e DIVMO) das pastagens cultivadas em relação à nativa, mostrando que a última apresenta limitação qualitativa para que a vaca possa expressar melhor o seu potencial genético para produção de leite.

A redução gradual da produção de leite tem sido relatada em vários estudos com vacas de corte (Leal \& Freitas, 1982; Alencar et al., 1988). Porém, têm sido encontrados diversos formatos de curvas, principalmente em função das condições alimentares aos quais os animais estão submetidos (Lamond et al., 1969; Bond \& Wiltbank, 1970). De acordo com resultados de pesquisa, o nível nutricional pós-parto parece ter maior influência na produção de leite do que no pré-parto (Wilson et al., 1969; Neville Jr., 1974; Richardson et al., 1977). Os resultados de Dunn et al. (1965) mostraram que, quando o tratamento foi de baixa energia pré-parto e alta pós-parto, a produção de leite aos 53, 82 e 109 dias de lactação, foi, respectivamente, de 7,8; 5,4; e $3,6 \mathrm{~kg} / \mathrm{dia}$, e quando o tratamento foi alta energia pré-parto e baixa pós-parto a produção foi de 5,$4 ; 5,2$; e $2,9 \mathrm{~kg} / \mathrm{dia}$. Estudando a produção de leite por um período de 90 dias, Senna (1996) verificou produção média diária de leite de 4,0 litros para vacas mantidas exclusivamente em pastagem nativa, 5,2 litros para as mantidas no período pré-parto em pastagem cultivada e no pósparto em pastagem nativa e 5,5 litros para vacas mantidas no pré-parto em pastagem nativa e pósparto em pastagem cultivada. Porém, Ribeiro (1989) não observou diferença significativa na produção de leite, em 182 dias lactação, quando vacas foram mantidas no período pós-parto em pastagem nativa ou pastagem cultivada de inverno (aveia mais azevém), 
Tabela 1 - Médias para produção diária de leite (L) de acordo com o tratamento alimentar, grupo genético da vaca e dia de lactação

Table 1 - Means for daily milk yield $(L)$ according to feed treatment, cow genetic group and lactation day

\begin{tabular}{|c|c|c|c|c|c|c|c|c|c|}
\hline \multirow[t]{2}{*}{$\begin{array}{l}\text { Tratamento alimentar } \\
\text { Feed treatment }\end{array}$} & \multirow[t]{2}{*}{$\begin{array}{l}\text { Grupo genético da vaca } \\
\text { Cow genetic group }\end{array}$} & \multicolumn{7}{|c|}{$\begin{array}{l}\text { Dia de lactação } \\
\text { Lactation day }\end{array}$} & \multirow[t]{2}{*}{$\begin{array}{l}\text { Média } \\
\text { Mean }\end{array}$} \\
\hline & & 14 & 42 & 70 & 98 & 126 & 154 & 182 & \\
\hline \multicolumn{10}{|l|}{$\begin{array}{l}\text { Pastagem cultivada } \\
\text { Cultivated pasture }\end{array}$} \\
\hline & $\begin{array}{l}\text { Charolês } \\
\text { Charolais }\end{array}$ & 5,72 & 5,33 & 5,41 & 5,85 & 4,89 & 4,49 & 3,24 & 4,99 \\
\hline & $\begin{array}{l}\text { Nelore } \\
\text { Nellore }\end{array}$ & 4,26 & 4,99 & 5,27 & 5,22 & 5,39 & 4,02 & 3,13 & 4,61 \\
\hline \multirow{4}{*}{$\begin{array}{l}\text { Média } \\
\text { Mean } \\
\text { Pastagem nativa } \\
\text { Native pasture }\end{array}$} & & 4,99 & 5,16 & 5,34 & 5,54 & 5,14 & 4,25 & 3,18 & $4,80^{*}$ \\
\hline & & & & & & & & & \\
\hline & $\begin{array}{l}\text { Charolês } \\
\text { Charolais }\end{array}$ & 5,97 & 4,66 & 4,38 & 4,14 & 3,76 & 3,14 & 2,03 & 4,01 \\
\hline & $\begin{array}{l}\text { Nelore } \\
\text { Nellore }\end{array}$ & 4,80 & 5,36 & 4,60 & 4,31 & 3,69 & 2,94 & 1,91 & 3,94 \\
\hline Média & & 5,38 & 5,01 & 4,49 & 4,22 & 3,72 & 3,04 & 1,97 & $3,98 * *$ \\
\hline \multicolumn{10}{|l|}{ Mean } \\
\hline
\end{tabular}

com médias de 2,95 e 3,78 1/dia, respectivamente. O autor comenta que a causa para este resultado foi devido às condições climáticas adversas que refletiram em baixa disponibilidade de MS/ha.

Ainda na Tabela 1, verifica-se que não houve efeito do grupo genético da vaca na produção diária de leite. Vacas Charolês produziram 4,50 L/dia em média, enquanto as Nelore 4,28 L/dia. Avaliando a produção de leite em vacas de corte por 238 dias, Cruz et al. (1997) verificaram que as vacas da raça Canchim produziram mais leite que as Nelore (5,37 vs $3,78 \mathrm{~kg} / \mathrm{dia}$ ), concordando com os resultados relatados por Alencar et al. (1993), que trabalhou com os mesmos grupos genéticos. Albuquerque et al. (1993) obtiveram produção de leite de 3,05 kg/dia para vacas da raça Nelore, em 207 dias de lactação, enquanto Marshall et al. (1976), trabalhando com vacas Charolês, verificaram produção média diária de 4,4 L, por 210 dias de lactação. Porém, estudos realizados no Sul do Brasil indicaram não haver diferença na produção diária de leite em função do grupo genético da vaca, como demonstraram Ribeiro et al. (1991), trabalhando com vacas Charolês (3,40 L) e Aberdeen Angus (2,99 L) e Senna (1996) trabalhando com vacas Charolês $(4,40 \mathrm{~L})$ e Nelore (3,9L), concordando com os resultados verificados no presente experimento. A explicação para este fato é de que vacas maiores dentro de uma mesma raça ou entre raças ou cruzamentos têm maiores exigências de manutenção, aumentando com isso, suas exigências nutricionais (Euclides Filho et al., 1984; Kress et al., 1990). Então, provavelmente, o aporte nutricional fornecido pelas pastagens no presente experimento, não foi suficiente para as vacas Charolês, de porte grande, expressarem todo seu potencial para produção de leite em relação as Nelore, de porte médio.

Na Tabela 2 estão apresentados os valores médios referentes à produção diária de leite de acordo com a classe de idade da vaca, tratamento alimentar e sexo do bezerro.

Houve interação significativa $(\mathrm{P}=0,0024)$ entre tratamento alimentar e classe de idade. Quando vacas foram mantidas em pastagem nativa, não houve diferença significativa entre a produção de leite nas diferentes classes de idade avaliadas, com média de 3,98 L/dia. Porém, vacas adultas mantidas em pastagem cultivada apresentaram produção $10,9 \%$ superior $(5,61 \mathrm{~L} /$ dia $)$ em relação às jovens $(5,00 \mathrm{~L} /$ dia $)$ e estas $29,5 \%$ em relação às velhas $(3,77 \mathrm{~L} /$ dia $)$, explicado principalmente por fatores fisiológicos, que proporcionam desempenhos máximos com a maturidade do animal (Cobuci et al., 2000), sendo as 
Tabela 2 - Médias para produção diária de leite (L), de acordo com a classe de idade da vaca, tratamento alimentar e sexo do bezerro

Table 2 - Means for daily milk yield (L), according to the cow age class, feed treatment and calf sex

\begin{tabular}{|c|c|c|c|c|}
\hline \multirow[t]{2}{*}{$\begin{array}{l}\text { Características } \\
\text { Characteristics }\end{array}$} & \multicolumn{3}{|c|}{$\begin{array}{c}\text { Classe de idade da vaca } \\
\text { Cow age class }\end{array}$} & \multirow[t]{2}{*}{$\begin{array}{l}\text { Média } \\
\text { Mean }\end{array}$} \\
\hline & $\begin{array}{l}\text { Jovens }(3-4 \text { anos }) \\
\text { Young }(3-4 \text { years old })\end{array}$ & $\begin{array}{l}\text { Adultas }(5-7 \text { anos }) \\
\text { Adult }(5-7 \text { years old })\end{array}$ & $\begin{array}{l}\text { Velhas }(8 \text { ou }+ \text { anos }) \\
\text { Old }(8 \text { or }+ \text { years old })\end{array}$ & \\
\hline \multicolumn{5}{|l|}{ Tratamento alimentar } \\
\hline $\begin{array}{l}\text { Pastagem nativa } \\
\text { Native pasture }\end{array}$ & $3,73 \mathrm{c}$ & $4,27 \mathrm{c}$ & $3,93 \mathrm{c}$ & 3,98 \\
\hline $\begin{array}{l}\text { Pastagem cultivada } \\
\text { Cultivated pasture }\end{array}$ & $5,00 \mathrm{~b}$ & $5,61 \mathrm{a}$ & $3,77 \mathrm{c}$ & 4,79 \\
\hline Média & 4,37 & 4,94 & 3,85 & \\
\hline $\begin{array}{l}\text { Mean } \\
\text { Sexo do bezerro } \\
\text { Calf sex }\end{array}$ & & & & \\
\hline $\begin{array}{l}\text { Macho } \\
\text { Male }\end{array}$ & $4,02 \mathrm{bc}$ & $4,80 \mathrm{ab}$ & $4,50 \mathrm{~b}$ & 4,44 \\
\hline Fêmea & $4,76 \mathrm{ab}$ & $5,08 \mathrm{a}$ & $3,11 \mathrm{c}$ & 4,57 \\
\hline $\begin{array}{l}\text { Female } \\
\text { Média } \\
\text { Mean }\end{array}$ & 4,39 & 4,94 & 3,80 & \\
\hline
\end{tabular}

a,b,c Médias seguidas por letras minúsculas diferentes, para o mesmo efeito, diferem pelo teste Tukey $(P<0,05)$.

$a, b, c$ Means followed by different small letters, for the same effect, differ by Tukey test $(P<.05)$.

variações na produção de leite mais expressivas quando o fator nutricional não é o limitante, pois conforme verificado na Tabela 3, vacas jovens e adultas apresentaram incremento na produção diária de leite na ordem de $26,0(5,00$ vs 3,73$)$ e $23,9 \%$ (5,61 vs 4,27$)$, respectivamente, quando as condições nutricionais foram melhoradas (pastagem nativa para cultivada). No entanto, não houve efeito do tratamento alimentar na produção de leite em vacas velhas, apresentando média de 3,85 L/dia. Além do efeito fisiológico, outro fator que pode explicar a maior produção de leite das vacas adultas seria o maior saldo de energia líquida para produção de leite, pois estas apresentam requerimentos nutricionais apenas de manutenção e produção, diferente das vacas jovens que ainda necessitam de requerimentos para crescimento. De maneira geral, vários autores citam resultados semelhantes aos obtidos no presente experimento, onde a produção de leite aumenta até os cinco ou seis anos, estabilizando-se após para começar a declinar a partir dos oito ou nove anos (Rutledge et al., 1971; Neville Jr. et al., 1974; Rovira, 1974; Robison et al., 1978; Souza et al., 1996). Porém, avaliando as características da produção de leite em um rebanho Nelore, Silva et al. (1995) verificaram que as produções máximas de leite ocorreram aos
10,1 anos de idade, com 1,53 L/dia.

Interação significativa também foi verificada entre sexo do bezerro e classe de idade da vaca $(\mathrm{P}=0,0011)$. Observou-se similaridade entre classes de idade, quando vacas amamentaram bezerros machos (4,44 L/dia). Porém, quando amamentaram fêmeas, vacas velhas produziram 34,7 e $38,8 \%$ menos leite $(3,11 \mathrm{~L} / \mathrm{dia})$, respectivamente, em relação às jovens $(4,76 \mathrm{~L} /$ dia $)$ e adultas $(5,08 \mathrm{~L} / \mathrm{dia})$, e $30,9 \%$ menos leite em relação às vacas velhas que amamentaram bezerros machos (4,50 L/dia).

Não houve efeito significativo do grupo genético do bezerro na produção de leite, embora vacas Charolês amamentando bezerros puros ou mestiços tenham produzido $4,9 \%$ mais leite em relação as Nelore (4,50 vs 4,28 L/dia), e vacas amamentando bezerros filhos de touros Nelore tenham produzido $8,3 \%$ mais leite do que àquelas amamentando bezerros filhos de touros Charolês (4,58 vs 4,20 L/dia). Resultados similares foram reportados por Rutledge et al. (1971), estudando dois rebanhos Hereford, e por Mendonça et al. (2000), onde vacas Hereford que amamentavam bezerros de raça paterna Nelore apresentaram produção de leite de $4,7 \mathrm{~kg} / \mathrm{dia}$, enquanto as que amamentavam bezerros filhos de touro Red Angus a produção foi de 5,1 kg/dia. Porém, Ribeiro et 
al. (1991) verificaram que vacas Charolês amamentando bezerros filhos de pai Nelore produziram mais leite (4,31 L/dia) do que as vacas Aberdeen Angus tanto amamentando bezerros puros $(2,99 \mathrm{~L} / \mathrm{dia})$ como mestiços $(3,35 \mathrm{~L} /$ dia $)$, porém não diferiram estatisticamente das vacas Charolês que amamentavam bezerros puros (3,40 L/dia). Reynolds et al. (1978) verificaram efeito significativo do genótipo do bezerro, onde vacas com bezerros cruzados produziram $16 \%$ a mais de leite. Segundo Cartwright \& Carpenter (1961) e Rovira (1974), animais cruzados mamam mais vezes ao dia e por período de tempo maior do que os definidos; fato associado à determinação genética para o temperamento e conduta do bezerro, que, mamando mais freqüentemente, estimularia maior produção de leite de suas mães.

\section{Composição do leite}

Os valores médios referentes ao percentual de gordura do leite de acordo com o grupo genético da vaca, tratamento alimentar e dia de lactação encontram-se na Tabela 3. Não houve efeito do tratamento alimentar na percentagem de gordura, sendo os valores médios obtidos de $4,71 \%$ quando os animais foram mantidos em pastagem cultivada e $4,58 \%$ quando em pastagem nativa, concordando com Ribeiro (1989) que verificaram médias variando de 3,2 a $3,7 \%$, e discordando de Senna (1996), que verificou menor teor de gordura no leite quando vacas foram mantidas em pastagem nativa. No entanto, houve interação significativa $(\mathrm{P}=0,0001)$ entre grupo genético da vaca e dia de lactação, conforme ilustrado na Figura 2. O teor de gordura verificado no leite de vacas Charolês apresentou comportamento linear, aumentando $0,0116 \%$ a cada dia de lactação, enquanto que em vacas Nelore o comportamento observado foi

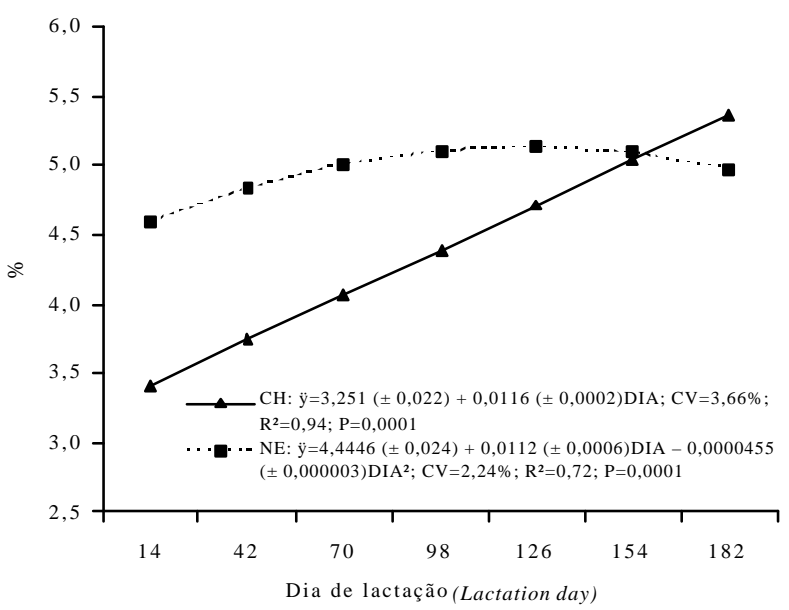

Figura 2 - Variação do teor de gordura do leite de acordo com o grupo genético da vaca e dia de lactação.

Figure 2 - Variation of milk fat content according to cow genetic group and lactation day.

Tabela 3 - Médias para teor de gordura do leite (\%) de acordo com grupo genético da vaca, tratamento alimentar e dia de lactação

Table 3 - $\quad$ Means for milk fat content (\%) according to cow genetic group, feed treatment and lactation day

\begin{tabular}{|c|c|c|c|c|c|c|c|c|c|}
\hline \multirow[t]{2}{*}{$\begin{array}{l}\text { Grupo genético da vaca } \\
\text { Cow genetic group }\end{array}$} & \multirow[t]{2}{*}{$\begin{array}{l}\text { Tratamento alimentar } \\
\text { Feed treatment }\end{array}$} & \multicolumn{6}{|c|}{$\begin{array}{l}\text { Dia de lactação } \\
\text { Lactation day }\end{array}$} & & \multirow[t]{2}{*}{$\begin{array}{l}\text { Média } \\
\text { Mean }\end{array}$} \\
\hline & & 14 & 42 & 70 & 98 & 126 & 154 & 182 & \\
\hline \multirow{4}{*}{$\begin{array}{l}\text { Charolês } \\
\text { Charolais }\end{array}$} & Pastagem cultivada & 3,11 & 3,80 & 4,00 & 4,40 & 4,66 & 5,29 & 5,70 & 4,42 \\
\hline & Cultivated pasture & & & & & & & & \\
\hline & $\begin{array}{c}\text { Pastagem nativa } \\
\text { Native pasture }\end{array}$ & 3,85 & 4,03 & 3,95 & 4,02 & 4,30 & 4,85 & 5,45 & 4,35 \\
\hline & $\begin{array}{l}\text { Média } \\
\text { Mean }\end{array}$ & 3,48 & 3,92 & 3,98 & 4,21 & 4,48 & 5,07 & 5,58 & $*$ \\
\hline \multirow{4}{*}{$\begin{array}{l}\text { Nelore } \\
\text { Nellore }\end{array}$} & Pastagem cultivada & 4,37 & 4,86 & 5,08 & 5,23 & 5,43 & 4,78 & 5,24 & 5,00 \\
\hline & Cultivated pasture & & & & & & & & \\
\hline & $\begin{array}{c}\text { Pastagem nativa } \\
\text { Native pasture }\end{array}$ & 4,52 & 5,24 & 5,01 & 4,91 & 4,60 & 4,89 & 4,52 & 4,81 \\
\hline & $\begin{array}{l}\text { Média } \\
\text { Mean }\end{array}$ & 4,45 & 5,05 & 5,05 & 5,10 & 5,02 & 4,84 & 4,88 & $* *$ \\
\hline
\end{tabular}

* $\hat{Y}=3,251( \pm 0,022)+0,0116( \pm 0,0002) D I A * ; C V=3,66 \% ; R^{2}=0,94 ; P=0,0001$.

** $\hat{Y}=4,4446( \pm 0,024)+0,0112( \pm 0,0006) D I A-0,0000455( \pm 0,000003) D^{2} A^{2} ; C V=2,24 \% ; R^{2}=0,72 ; P=0,0001$.

\# Dia de lactação (Lactation day). 
quadrático, com percentual máximo de gordura estimado de 5,13\% obtido aos 123 dias de lactação.

Entre os componentes do leite, a gordura é o que mais varia no decorrer da lactação. De maneira geral, a percentagem de gordura do leite aumenta gradualmente ao longo do dia de lactação, estando então, negativamente correlacionada com a produção de leite da vaca (Lamond et al., 1969; Rutledge et al., 1971; Schmidt \& Van Vleck, 1976; Richardson et al., 1977; Maynard et al., 1984). Avaliando 182 dias de lactação, Ribeiro et al. (1991) verificaram aumento linear diário de $0,0124 \%$ no teor de gordura do leite de vacas Charolês, o que é muito semelhante aos resultados do presente experimento.

No presente estudo, vacas Charolês apresentaram leite com teor de gordura médio de $4,38 \%$ e as Nelore de $4,9 \%$. Observa-se que as vacas Charolês apresentaram menor teor de gordura, provavelmente devido à produção de leite que numericamente foi superior neste grupo. Senna (1996) também verificou maior percentagem de gordura no leite de vacas Nelore $(3,3 \%)$ em relação as Charolês $(2,8 \%)$. Estudando a produção e composição do leite de um rebanho Nelore, Silva et al. (1995) verificaram teor de gordura médio de 4,5 \%, em 252 dias de lactação. Já Melton et al. (1967), avaliando 175 dias de lactação de vacas Charolês, Aberdeen Angus e Hereford, não verificaram diferença na percentagem de gordura (média de 2,8\%), embora vacas Charolês tenham produzido mais leite. O que também foi constatado por Ribeiro et al. (1991) ao comparar a percentagem de gordura do leite de vacas Charolês $(3,53 \%)$ e Aberdeen Angus (3,59\%).

$\mathrm{Na}$ Tabela 4, são apresentados os valores referentes ao percentual de extrato seco total de acordo com o grupo genético da vaca, tratamento alimentar e dia de lactação.

Não se verificou efeito $(\mathrm{P}=0,0787)$ do tipo de pastagem no teor de extrato seco total, sendo de $13,6 \%$ para pastagem cultivada e $13,3 \%$ para pastagem nativa, concordando com Ribeiro (1989) e Senna (1996), que reportaram valores médios oscilando entre 11,6 e $12,2 \%$. Porém, conforme demonstrado na Figura 3, houve interação significativa $(\mathrm{P}=0,0001)$ entre grupo genético da vaca e dia de lactação. Vacas Charolês apresentaram aumento linear diário de $0,0128 \%$ no teor de extrato seco total, com média de $13,12 \%$, e em vacas Nelore o comportamento da equação de regressão foi quadrático, com ponto estimado de máxima aos 117 dias e teor de 14,1\%, com média de $13,78 \%$. A variação no teor de extrato seco total é reflexo das oscilações do somatório dos

Tabela 4 - Valores médios para teor de extrato seco total do leite (\%), de acordo com o grupo genético da vaca, tratamento alimentar e dia de lactação

Table 4 - Mean values for milk total dry extract content (\%), according to the cow genetic group, feed treatment and lactation day

\begin{tabular}{|c|c|c|c|c|c|c|c|c|c|}
\hline \multirow[t]{2}{*}{$\begin{array}{l}\text { Grupo genético da vaca } \\
\text { Cow genetic group }\end{array}$} & \multirow[t]{2}{*}{$\begin{array}{l}\text { Tratamento alimentar } \\
\text { Feed treatment }\end{array}$} & \multicolumn{6}{|c|}{$\begin{array}{c}\text { Dia de lactação } \\
\text { Lactation day }\end{array}$} & & \multirow[t]{2}{*}{$\begin{array}{l}\text { Média } \\
\text { Mean }\end{array}$} \\
\hline & & 14 & 42 & 70 & 98 & 126 & 154 & 182 & \\
\hline \multicolumn{10}{|l|}{ Charolês } \\
\hline \multirow[t]{3}{*}{ Charolais } & $\begin{array}{l}\text { Pastagem cultivada } \\
\text { Cultivated pasture }\end{array}$ & 11,70 & 12,59 & 12,77 & 13,30 & 13,48 & 13,98 & 14,56 & 13,20 \\
\hline & $\begin{array}{c}\text { Pastagem nativa } \\
\text { Native pasture }\end{array}$ & 12,66 & 12,45 & 12,52 & 12,60 & 13,00 & 13,52 & 14,45 & 13,03 \\
\hline & $\begin{array}{l}\text { Média } \\
\text { Mean }\end{array}$ & 12,17 & 12,52 & 12,64 & 12,95 & 13,23 & 13,75 & 14,50 & $*$ \\
\hline \multicolumn{10}{|l|}{ Nelore } \\
\hline \multirow[t]{3}{*}{ Nellore } & $\begin{array}{l}\text { Pastagem cultivada } \\
\text { Cultivated pasture }\end{array}$ & 13,11 & 13,49 & 13,98 & 14,34 & 14,54 & 13,83 & 14,22 & 13,93 \\
\hline & $\begin{array}{c}\text { Pastagem nativa } \\
\text { Native pasture }\end{array}$ & 12,95 & 13,71 & 14,04 & 13,91 & 13,67 & 13,69 & 13,46 & 13,63 \\
\hline & $\begin{array}{l}\text { Média } \\
\text { Mean }\end{array}$ & 13,03 & 13,60 & 14,00 & 14,12 & 14,10 & 13,76 & 13,84 & $* *$ \\
\hline
\end{tabular}

* $\hat{Y}=11,8536( \pm 0,026)+0,0128( \pm 0,0002) D I A^{\#} ; C V=1,40 \% ; R^{2}=0,94 ; P=0,0001$

${ }^{* *} \hat{Y}=12,7908( \pm 0,02)+0,0228( \pm 0,0006)$ DIA $-0,0000976( \pm 0,000003) D^{2} A^{2} ; C V=0,80 \% ; R^{2}=0,90 ; P=0,0001$

\# Dia de lactação (Lactation day). 
demais componentes do leite, principalmente a gordura, que apresenta maior proporção, o que pode ser comprovado pela alta correlação entre percentagem de gordura e de extrato seco total $(\mathrm{r}=0,89 ; \mathrm{P}=0,0001)$ verificada no presente experimento, assim como reportados por Wilson et al. (1969) de 0,60 e Chenette \& Frahm (1981) de 0,36.

Resultados concordantes ao do presente experimento foram relatados por Senna (1996), estudando a composição do leite de vacas Charolês e Nelore (11,6 vs 12,2\%) e Cruz et al. (1997) trabalhando com vacas Nelore e Canchim (14,58 vs $13,58 \%)$. Avaliando a produção e composição do leite por 182 dias de lactação, Ribeiro et al. (1991) não verificaram diferença significativa entre vacas Charolês e Aberdeen Angus, sendo os valores obtidos de 11,9 e $11,8 \%$, respectivamente.

Na Tabela 5, são apresentados os percentuais médios de extrato seco desengordurado de acordo com o dia de lactação e grupo genético da vaca, que representa o conteúdo de extrato seco total desprovido do componente gordura. Analisar o comportamento do conteúdo dos demais componentes do leite sem a fração gordura torna-se interessante uma vez que este último é o componente que mais varia ao longo do dia de lactação, conforme já discutido anteriormente.

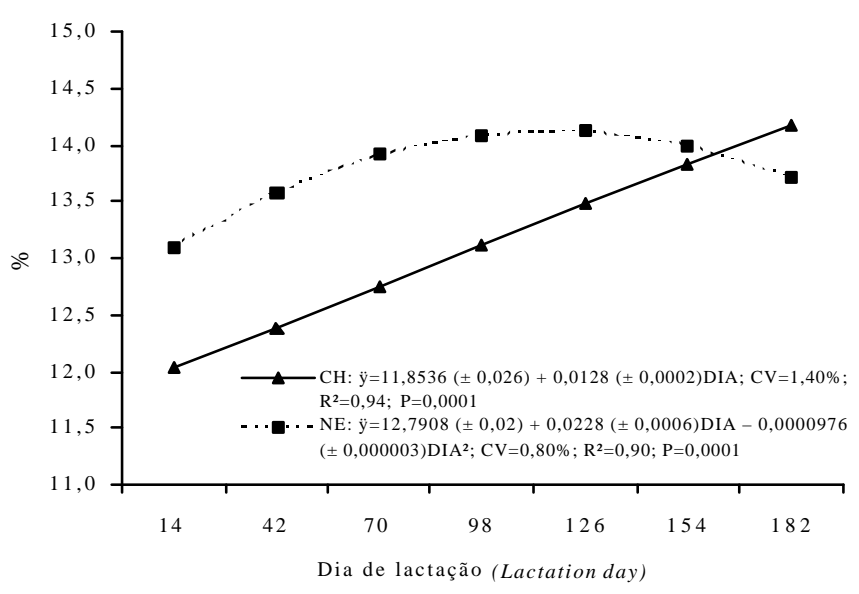

Figura 3 - Variação do teor de extrato seco total do leite, de acordo com o grupo genético da vaca e dia de lactação.

Figure 3 - Variation of milk total dry extract content, according to the cow genetic group and lactation day.
As médias dos teores de extrato seco desengordurado de acordo com o tratamento alimentar foram de $8,77 \%$ para pastagem nativa e $8,88 \%$ para pastagem cultivada, não apresentando diferença significativa $(\mathrm{P}=0,0610)$, concordando com Ribeiro (1989) e Senna (1996) avaliando diferentes seqüências de alimentação na produção e composição do leite de vacas de corte e discordando dos resultados de Wilson et al. (1969) que verificaram que o maior aporte nutricional no pós-parto ( $115 \%$ dos requerimentos) resultou em maior teor de extrato seco desengordurado no leite de vacas Angus-Holandês.

No entanto, houve efeito do grupo genético da vaca no percentual de extrato seco desengordurado, onde o leite de vacas Nelore apresentou maior teor $(8,91 \%)$ do que o das vacas Charolês $(8,74 \%)$ $(\mathrm{P}=0,0001)$. A correlação entre o percentual de extrato seco desengordurado com o de extrato seco total foi positiva e significativa $(r=0,22 ; \mathrm{P}=0,0001)$ no presente experimento, indicando que o maior teor de extrato seco total do leite de vacas Nelore influenciou no maior percentual de extrato seco desengordurado em relação às Charolês. Resultados concordantes com os do presente experimento foram relatados por Senna (1996), que verificou maior teor deste componente do leite em vacas Nelore em relação às Charolês $(9,0$ vs $8,8 \%)$.

O dia de lactação também influenciou significativamente $(\mathrm{P}=0,0005)$ o teor de extrato seco desengordurado. De acordo com a Figura 4, houve aumento linear de $0,00134 \%$ a cada dia de lactação, sendo que na média o percentual de extrato seco desengordurado foi de $8,83 \%$, o que está de acordo com Cundiff et al. (1974) e Cruz et al. (1997).

$\mathrm{Na}$ Tabela 6, encontram-se os valores médios para o percentual de lactose, de acordo com o grupo genético da vaca e dia de lactação, que constitui o principal carboidrato do leite, sendo sintetizado na glândula mamária.

Verifica-se que novamente vacas Nelore foram superiores $(\mathrm{P}=0,0001)$ em relação às Charolês $(5,14$ vs $4,94 \%$, respectivamente), concordando com Senna (1996), que ao estudarem a composição do leite de vacas Nelore e Charolês até os 90 dias pós-parto, verificaram percentual médio de 5,1 e 4,9\%, respectivamente. Já Ribeiro et al. (1991) verificaram similaridade no teor de lactose do leite, comparando vacas Charolês e Aberdeen Angus, com valores oscilando de 4,84 a 4,99\%.

Foi detectado efeito significativo do dia de lactação 
Tabela 5 - Valores médios para teor de extrato seco desengordurado do leite (\%), de acordo com o grupo genético da vaca e dia de lactação

Table 5 - Mean values for milk free-fat dry extract (\%), according to the cow genetic group and lactation day

\begin{tabular}{|c|c|c|c|c|c|c|c|c|}
\hline \multirow[t]{2}{*}{$\begin{array}{l}\text { Grupo genético da vaca } \\
\text { Cow genetic group }\end{array}$} & \multicolumn{7}{|c|}{$\begin{array}{l}\text { Dia de lactação } \\
\text { Lactation day }\end{array}$} & \multirow[t]{2}{*}{$\begin{array}{l}\text { Média } \\
\text { Mean }\end{array}$} \\
\hline & 14 & 42 & 70 & 98 & 126 & 154 & 182 & \\
\hline Charolês (Charolais) & 8,79 & 8,68 & 8,62 & 8,73 & 8,74 & 8,74 & 8,89 & $8,74 \mathrm{~B}$ \\
\hline Nelore (Nellore) & 8,83 & 8,64 & 8,87 & 8,96 & 9,04 & 8,98 & 9,07 & $8,91 \mathrm{~A}$ \\
\hline Média (Mean) & 8,81 & 8,66 & 8,75 & 8,85 & 8,89 & 8,86 & 8,98 & \\
\hline
\end{tabular}

$A, B$ Médias seguidas por letras maiúsculas diferentes, na coluna, diferem $(P<0,05)$ pelo teste Tukey.

$A, B$ Means followed by different capital letters, in the same column, differ by Tukey test $(P<.05)$.

Tabela 6 - Valores médios para teor de lactose do leite (\%), de acordo com o grupo genético da vaca e dia de lactação Table 6 - Mean values for milk lactose content (\%), according to the cow genetic group and lactation day

\begin{tabular}{lccccccc}
\hline $\begin{array}{l}\text { Grupo genético da vaca } \\
\text { Cow genetic group }\end{array}$ & \multicolumn{9}{c}{$\begin{array}{c}\text { Dia de lactação } \\
\text { Lactation day }\end{array}$} & \multicolumn{1}{c}{$\begin{array}{c}\text { Média } \\
\text { Mean }\end{array}$} \\
\cline { 2 - 7 } & 14 & 42 & 70 & 98 & 126 & 154 & 182 \\
\hline Charolês (Charolais) & 4,82 & 5,01 & 5,01 & 4,96 & 5,09 & 4,95 & 4,75 \\
Nelore (Nellore) & 5,00 & 5,14 & 5,25 & 5,08 & 5,26 & 5,18 & 5,07 \\
Média (Mean) & 4,91 & 5,08 & 5,13 & 5,02 & 5,17 & 5,07 & 4,91 \\
\hline
\end{tabular}

A,B Médias seguidas por letras maiúsculas diferentes, na coluna, diferem $(P<0,05)$ pelo teste Tukey.

$A, B$ Means followed by different capital letters, in the same column, differ by Tukey test $(P<.05)$.



Figura 4 - Variação do teor de extrato seco desengordurado do leite, de acordo com o dia de lactação.

Figure 4 - Variation of milk free-fat extract content, according to the lactation day.

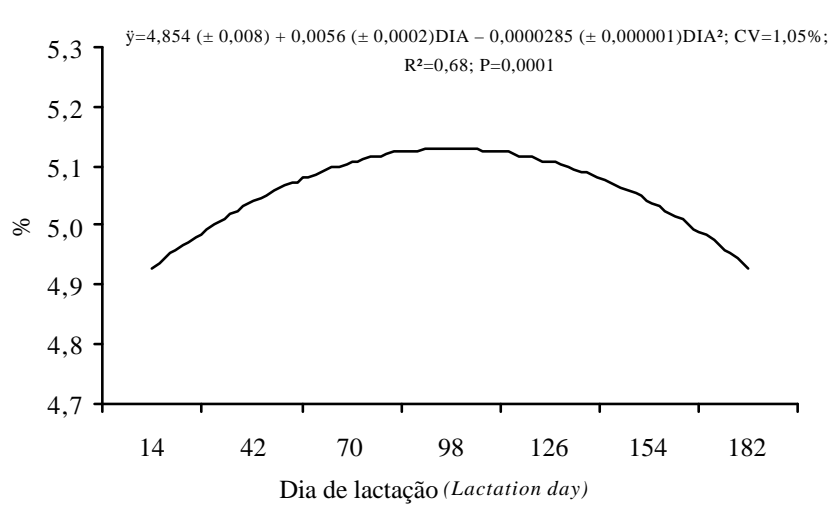

Figura 5 - Variação do teor de lactose do leite, de acordo com o dia de lactação.

Figure 5 - Variation of milk lactose, according to the lactation day. 
Tabela 7 - Valores médios para os componentes do leite, de acordo com a classe de idade da vaca e grupo genético da vaca

Table 7 - Mean values for milk components, according to the cow age class and cow genetic group

\begin{tabular}{|c|c|c|c|c|}
\hline \multirow[t]{2}{*}{$\begin{array}{l}\text { Características } \\
\text { Characteristics }\end{array}$} & \multicolumn{3}{|c|}{$\begin{array}{l}\text { Classe de idade da vaca } \\
\text { Cow age class }\end{array}$} & \multirow[t]{2}{*}{$\begin{array}{l}\text { Média } \\
\text { Mean }\end{array}$} \\
\hline & $\begin{array}{l}\text { Jovens }(3-4 \text { anos }) \\
\text { Young }(3-4 \text { years old })\end{array}$ & $\begin{array}{l}\text { Adultas }(5-7 \text { anos }) \\
\text { Adult }(5-7 \text { years old })\end{array}$ & $\begin{array}{l}\text { Velhas }(8 \text { ou }+ \text { anos }) \\
\text { Old }(8 \text { or }+ \text { years old })\end{array}$ & \\
\hline \multicolumn{5}{|c|}{ Gordura $(\%)$} \\
\hline $\begin{array}{l}\text { Charolês (Charolais) } \\
\text { Nelore (Nellore) } \\
\text { Média (Mean) }\end{array}$ & $\begin{array}{c}4,61 \\
5,26 \\
4,92 \mathrm{a}\end{array}$ & $\begin{array}{c}4,29 \\
4,73 \\
4,51 \mathrm{~b}\end{array}$ & $\begin{array}{c}4,15 \\
4,82 \\
4,52 \mathrm{~b}\end{array}$ & $\begin{array}{l}4,35 \mathrm{~B} \\
4,93 \mathrm{~A}\end{array}$ \\
\hline \multicolumn{5}{|c|}{$\begin{array}{l}\text { Extrato seco total }(\%) \\
\text { Total dry extract }(\%)\end{array}$} \\
\hline $\begin{array}{l}\text { Charolês (Charolais) } \\
\text { Nelore (Nellore) } \\
\text { Média (Mean) }\end{array}$ & $\begin{array}{c}13,24 \\
14,12 \\
13,68 \mathrm{a}\end{array}$ & $\begin{array}{c}12,98 \\
13,56 \\
13,27 \mathrm{~b}\end{array}$ & $\begin{array}{c}13,00 \\
13,76 \\
13,38 \mathrm{ab}\end{array}$ & $\begin{array}{l}13,07 \mathrm{~B} \\
13,81 \mathrm{~A}\end{array}$ \\
\hline \multicolumn{5}{|c|}{$\begin{array}{l}\text { Extrato seco desengordurado }(\%) \\
\text { Free-fat dry extract }(\%)\end{array}$} \\
\hline $\begin{array}{l}\text { Charolês (Charolais) } \\
\text { Nelore (Nellore) } \\
\text { Média (Mean) }\end{array}$ & $\begin{array}{l}8,68 \\
8,89 \\
8,78\end{array}$ & $\begin{array}{l}8,71 \\
8,97 \\
8,84\end{array}$ & $\begin{array}{l}8,83 \\
8,89 \\
8,86\end{array}$ & $\begin{array}{l}8,74 \mathrm{~B} \\
8,91 \mathrm{~A}\end{array}$ \\
\hline \multicolumn{5}{|c|}{$\begin{array}{l}\text { Lactose }(\%) \\
\text { Lactose }(\%)\end{array}$} \\
\hline $\begin{array}{l}\text { Charolês (Charolais) } \\
\text { Nelore (Nellore) } \\
\text { Média (Mean) }\end{array}$ & $\begin{array}{l}4,96 \\
5,17 \\
5,06\end{array}$ & $\begin{array}{l}4,98 \\
5,14 \\
5,06\end{array}$ & $\begin{array}{l}4,89 \\
5,11 \\
5,00\end{array}$ & $\begin{array}{l}4,94 \mathrm{~B} \\
5,14 \mathrm{~A}\end{array}$ \\
\hline
\end{tabular}

A,B Médias seguidas por letras maiúsculas diferentes, na coluna, diferem $(P<0,05)$ pelo teste Tukey.

$A, B$ Means followed by different capital letters, in the same column, differ $(P<.05)$ by Tukey test.

a,b Médias seguidas por letras minúsculas diferentes, na linha para o mesmo efeito, diferem $(P<0,05)$ pelo teste Tukey.

$a, b$ Means followed by different small letters, for the same effect in the line, differ $(P<.05)$ by Tukey test.

$(\mathrm{P}=0,0005)$ na percentagem de lactose do leite. Com o avanço da lactação, o teor de lactose apresentou comportamento quadrático (Figura 5), com ponto de máxima estimado de 5,13\% observado aos 98 dias de lactação. Resultados contrários foram relatados por Schmidt \& Van Vleck (1976) e Maynard et al. (1984), que verificaram que o teor de lactose decresceu lentamente até o final da lactação e por Marston et al. (1992), que ao avaliarem por 194 dias a produção e composição do leite em vacas Aberdeen Angus e Simental, observaram aumento linear e significativo no percentual de lactose do leite. Porém, Ribeiro (1989) relatou curva semelhante à observada no presente experimento quando o tratamento alimentar das vacas foi pastagem nativa no período pré-parto e cultivada de inverno no pós-parto, onde o teor de lactose aumentou até os 42-70 dias, decrescendo logo após.

Os valores médios dos componentes do leite de acordo com a classe de idade e grupo genético da vaca encontram-se na Tabela 7. Não foi verificada interação significativa para nenhum dos componentes do leite. Vacas jovens apresentaram maior percentual de gordura em relação às adultas e velhas (4,92; 4,51 e 4,52\%, respectivamente).

Quanto ao percentual de extrato seco total, o comportamento foi semelhante ao percentual de gordura, com vacas jovens apresentando teor superior às adultas (13,68 vs 13,27\%), com vacas velhas apresentando valor intermediário (13,38\%). Para os componentes extrato seco desengordurado e lactose, não foi verificada diferença significativa entre as diferentes idades. Vacas Nelore apresentaram valores superiores para todos os componentes do leite.

Não houve efeito do sexo do bezerro no percentual de gordura, extrato seco desengordurado e lactose do leite. Houve interação significativa para o percentual de extrato seco total do leite $(\mathrm{P}=0,0218)$, onde vacas Charolês amamentando machos apresentaram me- 
nor teor no leite do que vacas Charolês amamentando fêmeas $(12,82$ vs $13,33 \%)$ e estas inferior às vacas Nelore amamentando tanto machos $(13,83 \%)$ quanto fêmeas $(13,80 \%)$. Este resultado é explicado em função da variação numérica no teor de gordura do leite, uma vez que estas duas características são positivamente correlacionadas.

\section{Conclusões}

O uso de pastagem cultivada de inverno e de verão no período pós-parto promoveu maior produção de leite em vacas de corte Charolês e Nelore, bem como em vacas jovens e adultas, quando comparadas com vacas mantidas em pastagem nativa.

Vacas Charolês apresentaram produção de leite média diária similar às Nelore, embora estas últimas tenham produzido leite de melhor qualidade, devido à maior quantidade percentual de todos os componentes do leite.

Vacas jovens apresentaram maior percentual de gordura e extrato seco total em relação às adultas, enquanto o percentual de extrato seco desengordurado e lactose não variou com o avanço da idade.

$\mathrm{O}$ grupo genético do bezerro não influenciou a produção de leite das vacas.

\section{Literatura Citada}

ALBUQUERQUE, L.G.; ELER, J.P.; COSTA, M.J.R.P.Produção de leite e desempenho do bezerro na fase de aleitamento em três raças bovinas de corte. Revista Brasileira de Zootecnia, v.22, n.5, p.745-754, 1993 .

ALENCAR, M.M.; OLIVEIRA, F.T.T.; TAMBASCO, A.J. et al. Desenvolvimento pós-desmama e eficiência reprodutiva pós-parto em gado de corte: influência da produção de leite. Revista da Sociedade Brasileira de Zootecnia, v.22, n.6, p.1012-1018, 1993.

ALENCAR, M.M.; RUZZA, F.J.; PORTO, E.J.S. Desempenho produtivo de fêmeas das raças Canchim e Nelore. III. Produção de leite. Revista Brasileira de Zootecnia, v.17, n.4, p.317-328, 1988.

BOND, J.; WILTBANK, J.N. Effect of energy and protein on estrus, conception rate, growth and milk production of beef females. Journal of Animal Science, v.30, n.3, p.438-444, 1970.

BOWDEN, D.M. Feed utilization for calf production in the first lactation by 2 years-old F1 crossbred beef cows. Journal of Animal Science, v.51, p.304-315, 1981.

CARTWRIGHT, T.C.; CARPENTER, J.A. Effect of nursing habits on calf weights. Journal of Animal Science, v.2, p.904 (Abstracts), 1961.

CHENETTE, C.G.; FRAHM, R.R. Yield and composition of milk from various two-breed cross cows. Journal of Animal Science, v.52, n.3, p.483-492, 1981.

COBUCI, J.A.; EUCLYDES, R.F.; VERNEQUE, R.S. Curva de lactação na raça Guzerá. Revista Brasileira de Zootecnia, v.29, n.5, p.1332-1339, 2000.
CRUZ, G.M.; ALENCAR, M.M.; TULLIO, R.R. Produção e composição do leite de vacas das raças Canchim e Nelore. Revista Brasileira de Zootecnia, v.26, n.5, p.887-893, 1997. CUNDIFF, L.V.; GREGORY, K.E.; SCHWULST, F.J. et al. Effects of heterosis on maternal performance and milk production in Hereford, Angus and Shorthorn cattle. Journal of Animal Science, v.38, p.728-745, 1974.

DUNN, T.G.; WILTBANK, J.N.; ZIMMERMAN, D.R. Dam's energy intake on milk production and calf gains. Journal of Animal Science, v.24, p.586 (Abstracts), 1965.

EUCLIDES FILHO, K.; RESTLE, J.; OLSON, T.A. et al. Medidas de eficiência na produção de bezerros a partir de vacas de tamanho e habilidade leiteira diferentes. In: REUNIÃO ANUAL DA SOCIEDADE BRASILEIRA DEZOOTECNIA, 21., Belo Horizonte, 1984. Anais... Viçosa, MG: Sociedade Brasileira de Zootecnia, 1984. p.138.

HOLLOWAY, J.W.; STEPHEBSMD.F.; WHITEMAN, J.V. et al. Efficiency of production of 2-and 3-year-old Hereford, Hereford $x$ Holstein and Holstein cows. Journal of Animal Science, v.41, p.855-867, 1975.

KRESS, D.D.; DOORNBOS, D.E.; ANDERSON,D.C. Performance of crosses among Hereford, Angus and Simmental cattle with different levels of Simmental breeding: V. Calf production, milk production and reproduction of three to eight-year-old dams. Journal of Animal Science, v.68, p.1910-1921, 1990.

LAMOND, D.R.; HOLMES, J.H.G.; HAYDOCK, K.P. Estimation of yield and composition of milk produced by grazing beef cows. Journal of Animal Science, v.29, p.606-611, 1969.

LEAL, T.C.; FREITAS, J.E. Correlação entre produção de leite e ganho de peso de bezerros da raça Charolesa. Anuário Técnico do IPZFO, v.9, p.91-101, 1982.

MARSHALL,D.A.;PARKER,W.R.;DINKEL,C.A.Factors affecting efficiency to weaning in Angus, Charolais and reciprocal cross cows. Journal of Animal Science, v.43, p.1176-1187, 1976.

MARSTON, T.T.; SIMMS, D.D.; SCHALLES, R.R. et al. Relationship of milk production, milkexpected progeny difference, and calf waning weight in Angus and Simmental cow-calf pairs. Journal of Animal Science, v.70, p.3304-3310, 1992.

MAYNARD, L.A.; LOOSLI, J.K.; HINTZ, H.F. et al. Nutrição animal. 3.ed. Rio de Janeiro: Freitas Bastos, 1984. 736p.

MELTON,A.A.; RIGGS,J.K.; NELSON,L.A.etal. Milk production, composition and calf gains of Angus, Charolais and Hereford cows. Journal of Animal Science, v.26, p.804-809, 1967.

MENDONÇA, G.; PIMENTEL, M.A.; CARDELLINO, R.A. et al. Produção de leite em bovinos de corte I. Produção de leite de primíparas com bezerros cruzas Bos taurus $x$ Bos indicus e Bos taurus $x$ Bos taurus. In: REUNIÃO ANUAL DA SOCIEDADE BRASILEIRA DE ZOOTECNIA, 37., Viçosa, MG. Anais... Viçosa: Sociedade Brasileira de Zootecnia, 2000/Gnosis, [2000]. CD-ROM. Manejo e Reprodução. 0795.

NEVILLE JR., W.E.; WARREN, E.P.; GRIFFEY, W.A. Estimates of age effects on milk production in Hereford cows. Journal of Animal Science, v.38, v.1, p.1-5, 1974.

POLLI, V.A.; LOBATO, J.F.P. Utilização de pastagem temperada por diferentes categorias do rebanho. I. Vacas com cria. In: REUNIÃO ANUAL DA SOCIEDADE BRASILEIRA DE ZOOTECNIA, 22., 1985, Camboriú. Anais... Camboriú: Sociedade Brasileira de Zootecnia, 1985, p.503.

QUADROS, S.A.F.Q.; LOBATO, J.F.P. Efeitos da lotação animal na produção de leite de vacas de corte primíparas e no desenvolvimento de seus bezerros. Revista Brasileira de Zootecnia, v.26, n.1, p.27-33, 1997. 
REYNOLDS, W.L.; DeROUEN, T.M.; BELLOWS, R.A. Relationships of milk yield of dam to early growth rate of straightbred and crossbred calfs. Journal of Animal Science, v.47, n.3, p.584-594, 1978.

RIBEIRO, E.L.A. Influência de diferentes seqüências de pastagens na produção de leite e no desempenho de vacas de dois grupos genéticos. Santa Maria: Universidade Federal de Santa Maria, 1989. 149p. Dissertação (Mestrado em Zootecnia) - Universidade Federal de Santa Maria, 1989.

RIBEIRO, E.L.A.; RESTLE, J. Desempenho de terneiros Charolês e Aberdeen Angus puros e seus mestiços com Nelore.Pesquisa Agropecuária Brasileira, v.26, n.8, p.1145-1151, 1991.

RIBEIRO, E.L.A.; RESTLE, J.; PIRES, C.C. Produção e composição do leite de vacas Charolês e Aberdeen Angus amamentando bezerros puros ou mestiços. Pesquisa Agropecuária Brasileira, v.26, n.8, p.1267-1273, 1991.

RICHARDSON, F.D.; OLIVER, J.; CLARKE, G.P.Y. Analisis of some factors wich affect the productivity of beef cows and of their calfs in a marginal rainfall area of Rhodesia. 2. The yield and composition of milk of suckling cows. Animal Production, v.25, p.359-372, 1977.

ROBISON, O.W.; YUSUFF, M.K.M.; DILLARD, E.U. Milk production in Hereford cows I. Means and correlations.Journal of Animal Science, v.47, n.1, p.131-135, 1978.

ROVIRA, J. Manejo nutritivo de los rodeos de cria em pastoreo. Montevideo: Hemisferio Sur. 1996. 288p.

ROVIRA, J. Reproduccion y manejo de los rodeos de cria. Montevideo: Hemisferio Sur. 1974. 293p.

RUTLEDGE, J.J.; ROBISON, O.W.; AHLSCHWEDE, W.T. et al. Milk yield and its influence on 205-day weight of beef calfs. Journal of Animal Science, v.33, p.563-567, 1971.

STATISTICAL ANALYSES SYSTEMS. SAS Institute - user's guide. Version 6, Cary: 1997. 1052p.
SCHMIDT, G.H.; Van VLECK, L.D. Bases científicas de la producción lechera. Zaragoza: Acríbia. 1976, 583p.

SENNA, D.B. Desempenho reprodutivo e produção de leite de vacas de quatro grupos genéticos, desterneiradas precocemente, submetidas a diferentes períodos de pastagem cultivada. Santa Maria: Universidade Federal de Santa Maria, 1996. 85p. Dissertação (Mestrado em Zootecnia) - Universidade Federal de Santa Maria, 1996.

SILVA, M.V.G.B.; MARTINEZ, M.L.; LEMOS, A.M. Efeitos de meio ambiente sobre as características de produção de leite e gordura, percentagem de gordura e duração da lactação de um rebanho Nelore. Revista Brasileira de Zootecnia, v.24, n.2, p.317-325, 1995.

SOUZA, E.M.; MILAGRES, J.C.; REGAZZI, A.J. et al. Efeitos de fatores genéticos e de meios ambiente sobre a produção de leite em rebanhos de Gir leiteiro. Revista Brasileira de Zootecnia, v.25, n.4, p.889-901, 1996.

TOTUSEK, R.; ARNETT, D.W.; HOLLAND, G.L. et al. Relation of estimation method, sampling interval and milk composition to milk yield of beef cows and calf gain. Journal of Animal Science, v.37, n.1, p.153-158, 1973.

WILM, H.G.; COSTELLO, D.F.; KLIPPLE, G.E. Estimating forage yield by the double-sampling methods. Journal of American Society of Agronomy, v.36, p. 194-203, 1944.

WILSON, L.L., GILLOOLY, J.E., RUGH, M.C., et al. Effects of energy intake, cow body size and calf sex on composition and yield of milk by Angus-Holstein cows and preweaning growth rate of progeny. Journal of Animal Science, v.28, p.789, 1969.
Recebido em: 06/06/02

Aceito em: 07/12/02 